\title{
RECOVERY OF THE MOBILITY OF THE SCAPULO-HUMERAL JOINT USING BALL
}

\author{
C.G. CĂTUNĂ ${ }^{1} \quad$ I.M. BUȚU ${ }^{1}$
}

\begin{abstract}
In this paper we aim to achieve a prophylactic kinetic program and recovery of mobility of the scapulo-humeral joint with the help of exercises specific to various ball sports (handball, gymnastics) to diversify the exercises available to the physiotherapist. We aim to emphasize the value of the physical therapy program in the functional recovery of patients and to improve existing programs by increasing the variety of exercises, adapting ball-specific exercises to medical recovery goals.
\end{abstract}

Key words: mobility, recovery, ball, scapulo-humeral.

\section{Introduction}

The number of shoulder surgeries is an essential therapeutic alternative for many degenerative joint or traumatic disorders that are accompanied by pain and functional disability. The treatment of joint disease does not end with surgery [12].

Treatment should include posttraumatic or postoperative treatment and a recovery program that is a mandatory and essential condition for achieving the overall goals of treatment: no pain, improved joint function, and improved quality of life for patients [13].

The role of exercise is essential, not only in initiating and supporting the recovery protocol, but also in the early detection of complications, in adapting the rehabilitation regime to local and general evolution [8].

Problems in the scapulo-humeral joint in patients of all age groups occur as a result of factors that lead to imbalances in the dynamics of the shoulder [1]. These consist of severe trauma, overload on the affected limb segment, repetitive movements, repeated microtrauma, incorrect joint biomechanics, major differences in tone and strength between agonist and antagonist muscles, etc [10].

In order for the patients to become aware of the exercises and make them more efficient, minimum theoretical training is necessary, meaning that patients will be taught how to perform the respiratory types and procedures in order

\footnotetext{
${ }^{1}$ Spiru Haret University, Berceni Road, no. 24, sector 4, Bucharest
} 
to properly execute the content of the program [19].

\section{Objective}

This research is addressed to physiotherapists whose patients have undergone astroscopic or classical surgery (autoplasty, osteosynthesis, etc.), as well as various shoulder diseases (sprains, contusions, bursitis, etc.) [4]. The research contains a series of general recovery exercises corroborated with the specific means of ball sports that can vary and supplement the baggage of exercises that lead to the recovery of joint mobility in patients who need to recover the scapulohumeral joint.

Another objective is to bring to the fore the indisputable fact that the physiotherapy exercises corroborated with the specific means of ball sports, adapted for recovery have increased efficiency and lead to the recovery of muscle strength and muscle tone [6].

We also consider that these exercises have an increased attractiveness, knowing that ball sports are very popular in general due to their dynamism.

On the one hand, by breathing in and breathing out in a complete manner, in the attempt to use as much as possible of the lungs capacity, we provide more oxygen for the entire body through the blood system and we improve nutrition of each and every cell, body and brain function at full load, while daily stress decreases for each of us [19].

\section{Material and Methods}

Unfortunately, the research during the "Covid" period means that the diversity of the methods we could have is limited to the methods that involve researching and studying the specialized literature to which we can contribute from the experience gained [2], [3] ,[7]. Thus, the main methods used were the documentation method, the bibliographic study method and the observation method.

The scapulo-humeral joint consists of three joints and two sliding planes, arranged so as to give it a very high degree of mobility [24]. Unfortunately, this affects the level of stability conferred especially by the tendons and muscles [25].

In case of mechanical overload on the shoulder, following various traumas, or recovery from surgery, due to pain, the mobility of this joint decreases being necessary and indicated specialized physiotherapy recovery [9].

The scapulo-humeral joint allows, most gestures in everyday life, being very important [11]. Physiotherapy in this case, has a prophylactic role but also recovery preventing the appearance of simple painful shoulder or loss of mobility through the appearance of fibrosis, periarthritis, pseudo-paralytic shoulder or other specific dysfunctions [15].

The muscle groups targeted by this recovery program include the muscles that control the mobility of the shoulder as well as the trunk muscles:

- Deltoid (located anterior, posterior and above the scapulo-humeral joint)

- Infraspinatus (supports the shoulder joint)

- Subscapular (on the anterior face of the shoulder blade)

- Biceps (on the front of the arm)

- Large and small round (supports the shoulder joint)

- Triceps (on the back of the arm)

- Trapeze 
- The rhomboid

- Supraspinatus (supports the shoulder joint) [14].

Exercise program to relieve shoulder pain [16].

Specific recovery techniques may include stretching exercises, as well as those aimed at strengthening the muscles in the shoulder [17]. These exercises will focus on improving flexibility, increase range of motion, providing greater comfort and ease of movement [20].

Dynamic stretching exercises determine a good perception of body movements, develops balance and proprioception provides benefits to the brain being informed about the static and balance bones, joints, tendons and muscles to be used during specific effort itself [21].

Program of exercise needs to be performed three to six times a week. In the first stage, the duration will be 10 minutes and then it will gradually increase as the joint becomes stronger and more flexible. During the exercise program, the person will focus on relaxing and releasing any tension in the shoulder area.

1. Sitting or sitting on a chair, with the ball supported on the head with the valid hand, rolling it on the palm, by bending the head forward with return, rotating to the right and left, or making a semicircle, to stretch the muscles on the affected side. Up to 1 minute with a 30-second break, repeat 3-5 times.

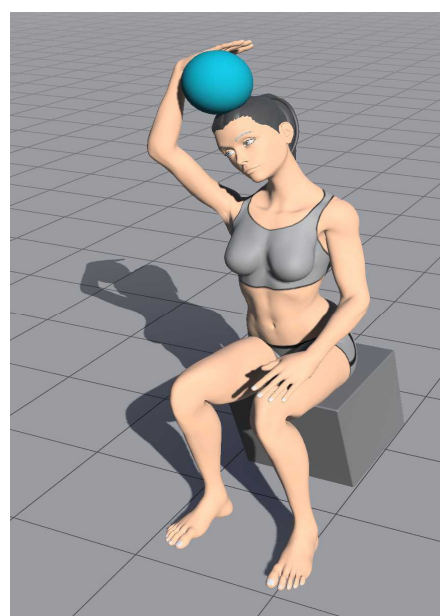

Fig. 1. Rolling the ball

2. Standing or sitting on a chair with the ball in the right hand, raising the right arm forward, the left arm bends, and the hand supports the right elbow, bringing the right arm to the left horizontally, without bending the arm. Repeat 3-5 times on each side, maintaining this position for up to a minute.

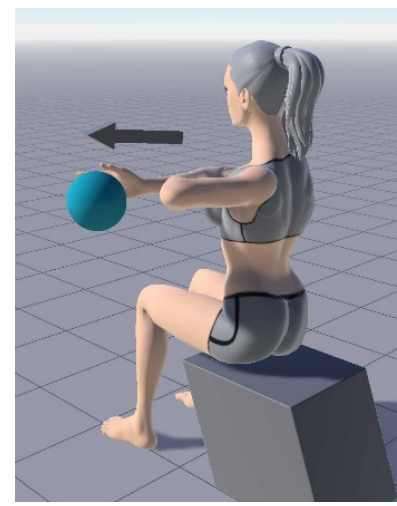

Fig. 2. Bringing the arm horizontally

3. Standing away, the ball held with both hands back, at the level of the pelvis, lifting the arms slightly, without moving the torso. Hold the position for up to 30 seconds, repeat 3-5 times. 


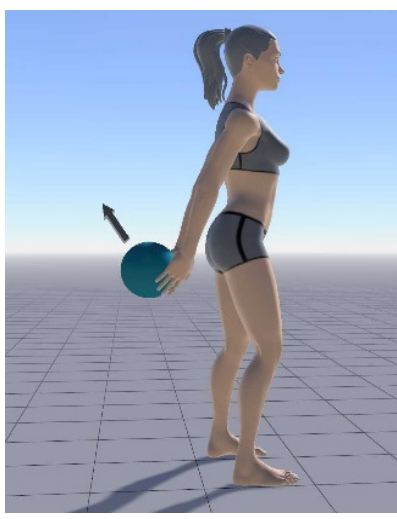

Fig. 3. Raise your arms back

4. Sitting on a chair, the ball held with both hands, raising the arms forward, bending the elbows at $90^{\circ}$, the right elbow is positioned in the fold of the left elbow. The same movement is performed with the other arm. Hold the position for 15 seconds.

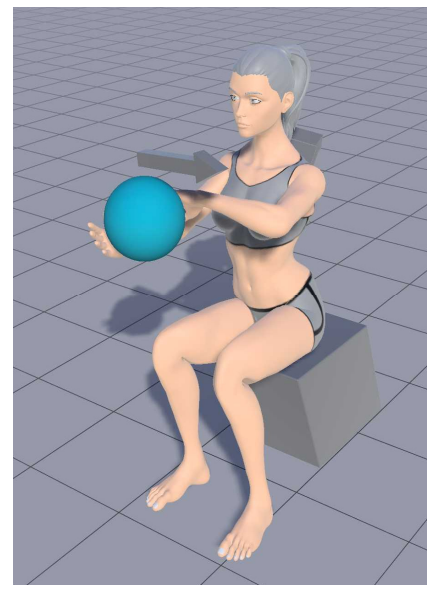

Fig. 4. Example of exercise 4

5. Sitting with the feet apart the ball held with both hands forward, twisting the torso to the right, bringing the right arm back so that the body does not twist from the pelvis with the lower limbs. Repeat the exercise to the left, holding the ball in your left hand. Hold the position for up to 30 seconds, repeating the movement 3-5 times on each side.

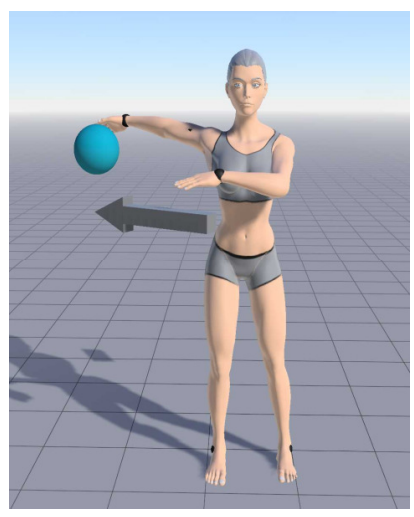

Fig. 5. Twisting the torso with the arm back

6. Standing with the arms forward, the ball held with the right hand, swinging the right arm in the sagittal plane backwards, returning by passing the ball in the left hand and repeating the movement with the left arm [5].

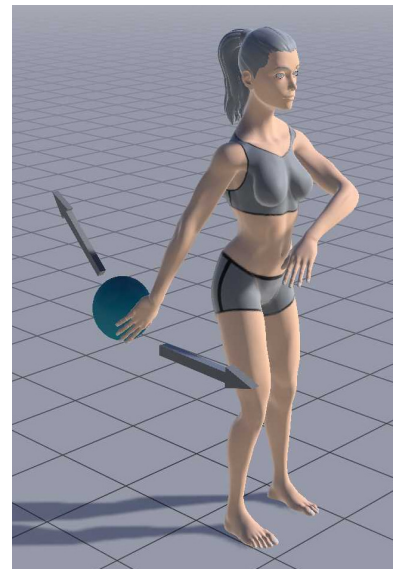

Fig. 6. Swinging the arm in the sagittal plane

7. Standing apart, arms sideways, ball in right hand, raising arms up, passing the ball in left hand, lowering arms sideways, and resuming exercise on the left. 


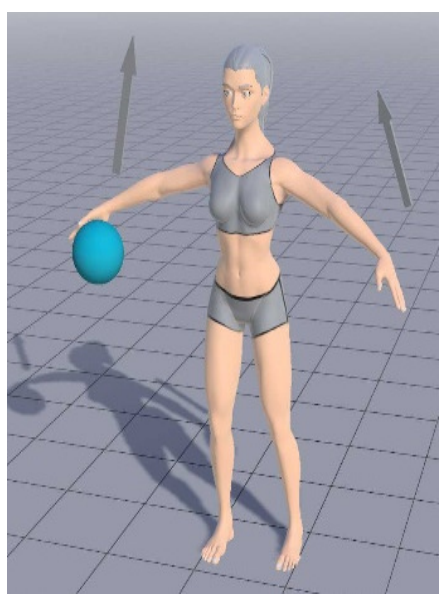

Fig. 7. Raise your arms upwards with the ball passing from one hand to the other

8. On a knee with the lateral arm, parallel to the ground and the elbow bent at $90^{\circ}$, perform multiple dribbles 3 sets of 30 seconds with a break of 15 seconds [26].

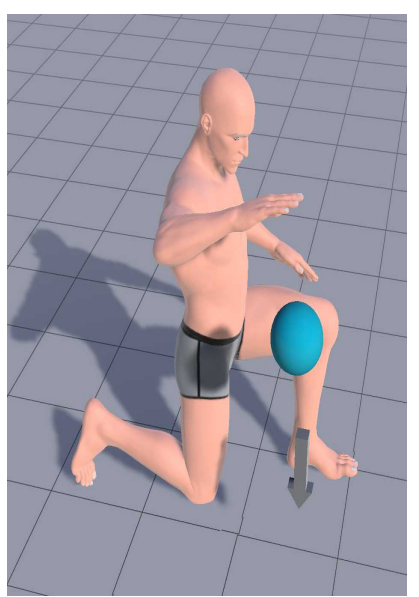

Fig. 8. Dribbling from one knee

9. On one knee with the lateral arm, parallel to the ground, perform multiple dribbles 3 sets of 30 seconds with a break of 15 seconds [30].

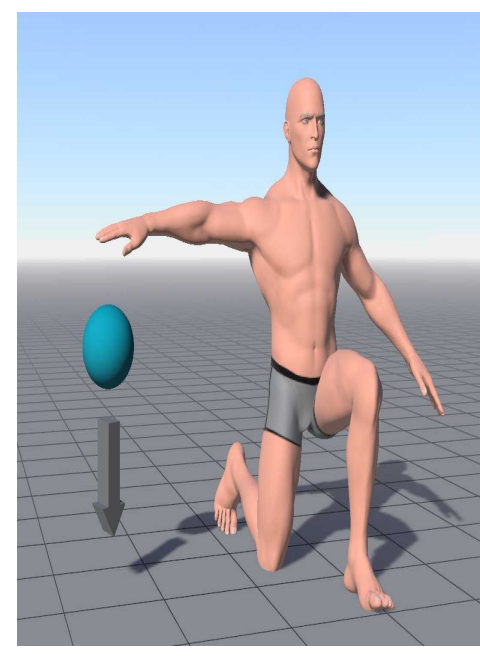

Fig. 9. Dribbling to the side

10. From the back-and-forth leg game, repeat back passes after the ball returns from the wall. Execute 3 sets of 20 passes with a break of 20 seconds [29].

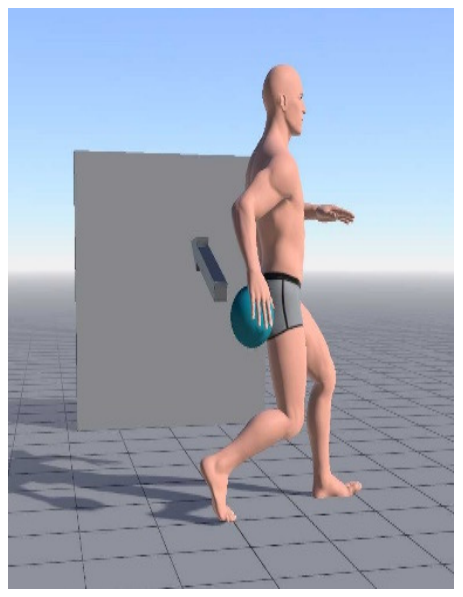

Fig. 10. Pass on the back

11. From the game of feet, picking up the ball rolled on the ground and the bird back over the same shoulder. $2 \times 15$ repetitions with a break of 20 seconds [28]. 


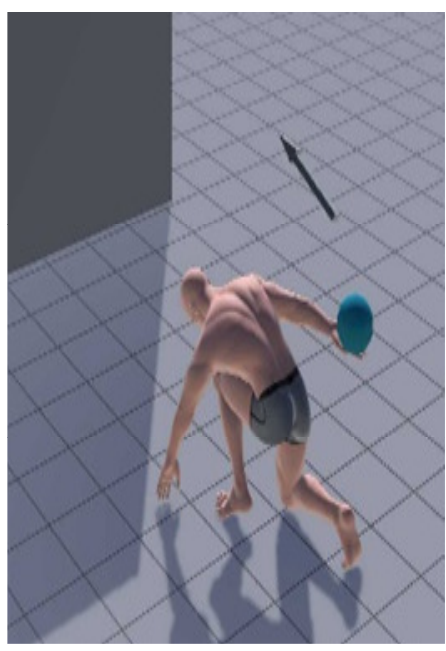

Fig. 11. The bird backs over the same shoulder

12. Passes thrown over the shoulder with the ground from the game of feet, repeated in front of a wall. Two sets of 20 passes with a 30-second break [27].

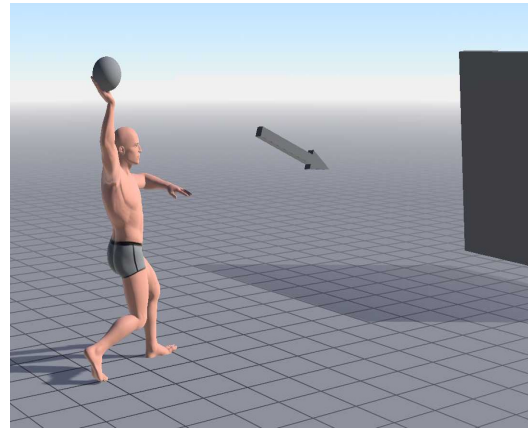

Fig. 12. Passes thrown over the shoulder

13. From the rib cage, dribble is performed, keeping the elbow at $90^{\circ}$ and glued to the body, 3 series of 30 seconds with a break of 15 seconds. (for infraspinatus and small round muscle) [31].

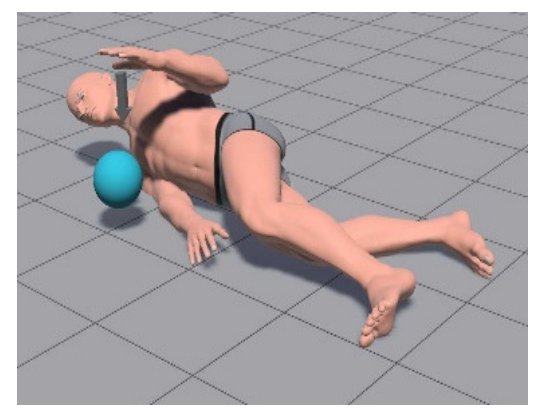

Fig. 13. Dribbling with internal rotation

14. From lying on your back, perform multiple dribbles on the side opposite the arm, 3 sets of 20 seconds with a break of 15 seconds [32].

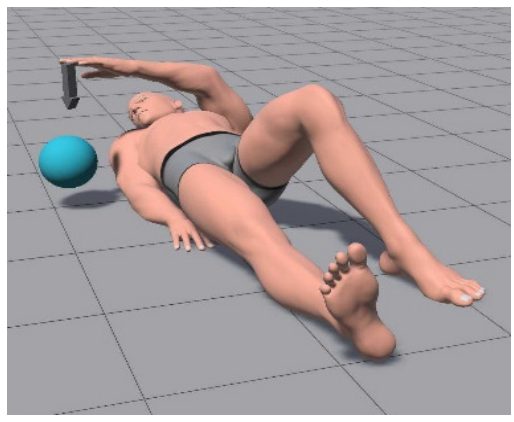

Fig. 14. Dribbling from the back

15. From the game of feet, pronounced passes repeated with the return of the ball from the wall. Three 20-second sets with a 15-second break [23].

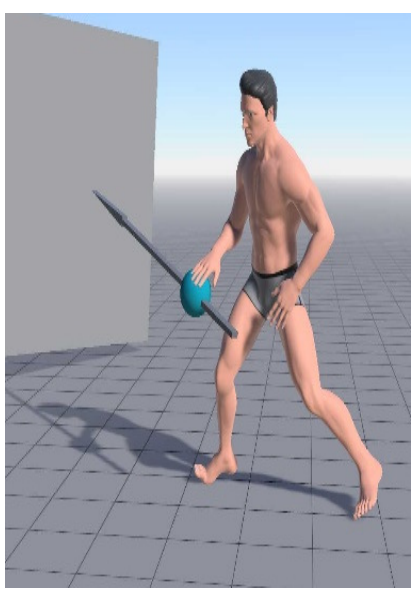

Fig. 15. Pronation passes 


\section{Results and Discussions}

The recovery program is not a substitute for specialized supervision. This will be done under the supervision of a physiotherapist to Directions the attending physician, each procedure being adapted from case to case. DRILLS can be performed and the home individually after they will be repeated by face with a frame specialised and mastered correct [22].

Physical training without proper breathing will lead to rapid fatigue and lower results in terms of benefits gained after practicing the physical training program, benefits represented by the relaxation of the entire body, stress relief, improvement of internal organs efficiency and the entire body respectively optimization of quality of life [18].

We aim to emphasize the value of the program therapist in the functional recovery of patients and improve existing programs by increasing the variety of exercises, adapting specific exercises with the ball to the goals of medical recovery.

\section{Conclusions}

These results can be useful and indicative in the design of rehabilitation programs to adapt care and allow full recovery of functional parameters.

Exercise provides the means for these patients to become functionally efficient.

The specialist physiotherapist must apply the different principles and techniques adapted to each type of patient [23].

\section{Acknowledgements}

Thank you to everyone who was part of the YOUTH IN THE PERSPECTIVE OF THE OLYMPIC MOVEMENT Conference!

\section{References}

1. Andrews, J., Harrelson, G., Wilk, K., Physical Rehabilitation of the Injured Athlete, 4th Edition. Philadelphia, Elsevier Saunders Inc. Publishing House, USA, 2012.

2. Anton, B., Buzescu, A.: Sports Traumatology. Bucharest, Cartea Universitară Publishing House, 2005.

3. Aramescu, E.T.: Methodological approaches of risk factors in sport traumatology in volleyball. In: Sports Medicine Journal, no. 6, p. 390, 2006.

4. Bratu, M.: Recovery in sports traumatology. Bucharest, University Publishing House, 2013.

5. Buţu, I.M.: Rhythmic gymnastics general bases, course in IFR technology. Bucharest, Romania of Tomorrow Foundation Publishing House, 2015.

6. Cătună G.C., Alupoaie M.: Handball Course in IFR technology. Romania of Tomorrow Foundation Publishing House, Bucharest, 2012.

7. Cordun, M.: Medical Kinetology. Bucharest, Axa Publishing House, 1999.

8. Creţu, A.: Recovery in sports. Bucharest, Alexandru Publishing House, 2003.

9. Dhuhaibawi, Al. A.: The incidence of scapulohumeral dislocation in different sports and possibilities of therapeutic intervention. In: Revista

10.Discobolul, X17, UNEFS, Bucharest, 2018.

11. Dickens, J. et al.: Return to play and recurrent instability after in season anterior shoulder instability; a prospective multicenter study. In: Am J Sports Med., 2014, 42 (12), p. 2842-50. 
12. Dines, M.D., Cato, T.L., Williams, G., R.: The shoulder. Philadelphia, Saunders Publishing, 2009.

13. Donatelli, A.R.: Physical therapy of the shoulder, 3rd Edition. New York, Churchill Livingstone Publishing House, 1997.

14. Donatelli, A.R.: Physical therapy of the shoulder, 4th Edition. Philadelphia, Churchill Livingstone Publishing House, 2004.

15. Dragan, I.: Sports Medicine. Bucharest, Medical Publishing House, 2002.

16. El-Bsat, R.M.: Physiotherapy for physiotherapists. Bucharest, Semne Publishing House, 2002.

17. James, R.A., Kevin, E.W., Michael, M., R.: The Athlete's Shoulder. Kindle Publishing, 2nd Edition, 1994.

18. Jianu A., Macovei S.: Respiratory gymnastics, means of improving the health condition to hypertensive persons. In: Ovidius University Annals, Series Physical Education and Sport / Science, Movement and Health, vol. XIII, Issue 2 supplement, September 2013, 13 (2), p.629 -635.

19. Jianu, A.: Influence of respiratory gymnastics in elderly hypertensive subjects. In: Ovidius University Annals, Series Physical Education and Sport / Science, Movement and Health, vol. 16, no. 2 SI, 2016, p. 502-507.

20. Jianu, A.: Practical and methodical components of conducting respiratory gymnastics programs involving hypertensive subjects. In: ProcediaSocial and Behavioral Sciences, 117, 2014, p. 517-521.

21. Parker, N.J., Parker, M.P.: Frozen Shoulder. Philadelphia, ICON Health Care Publishing, 2004.
22. Parker, N.J., Parker, M.P.: Shoulder pain, Health Care Publishing, 2004.

23. Parker, N.J., Parker, M.P.: Shoulder tendonitis. In: Health Care Publishing, 2002.

24. Patry, L., Rossingnol M., Costa, M.J., Buillargeon, M.: Shoulder Tendinitis. Montreal, MultiMonders Publishing, 1998.

25. Sidenco, E. L.: Practical guide for joint and muscle evaluation in physiotherapy. Bucharest, "Romania of Tomorrow" Foundation Publishing House, 2005.

26. Tache, O.G.: General Medicine Medical Recovery. Bucharest, Carol Davila Publishing House, 2013.

27.https://ro.scribd.com/doc/182785155/ Program-kinetic-de-recuperare-inluxatii-recidivante-de-umar-lajucatorii-de-handbal;

28.https://www.doctorortoped.ro/recupe rare/program-recuperare-umar;

29.https://www.ortopedumar.ro/recuper are-umar/

30.https://centrokinetic.ro/fiziokinetotera pia-explicata/totul-desprerecuperare/periartritascapulohumerala/

31.https://anatomie.romedic.ro/articulati a-scapulohumerala-umarul

32.https://pdfcoffee.com/rolulkinetoterapiei-in-recuperarea-luxatieiscapulo-pdf-free.html

33.https://www.kinetoterapierecuperare medicala.ro/periartrita-scapulohumerala-psh/ 